\title{
In Vitro Studies of Bioactive Glass/polyhydroxybutyrate Composites
}

\author{
André Oliveira Paiva ${ }^{\text {a*, Maria Gabriela Duarte }}$, Maria Helena Vaz Fernandes ${ }^{\mathrm{b}}$, \\ Maria Helena Gilc, Necésio Gomes Costa ${ }^{\mathrm{d} *}$ \\ ${ }^{a}$ Science Institute, Federal University of Itajubá, 37500-9002 Itajubá - MG, Brazil \\ ${ }^{\mathrm{b}}$ Department of Ceramics and Glass Engineering, University of Aveiro, \\ Santiago Campus, 3810, Portugal \\ ${ }^{c}$ Department of Chemical Enginnering, University of Coimbra, 3030 Polo II, \\ Pinhal de Marrocos, Coimbra, Portugal \\ ${ }^{\mathrm{d}}$ Mechanical Engineering Institute, Federal University of Itajubá, \\ 37500-902 Itajubá - MG, Brazil
}

Received: September 4, 2006; Revised: October 24, 2006

\begin{abstract}
Bioactive materials can help bone reparation and regeneration by offering support to bone growth. In vitro studies of bioactive glass/polyhydroxybutyrate composites were carried out to evaluate the influence of the composition on the bioactivity through the presence of calcium phosphate $(\mathrm{Ca}-\mathrm{P})$ on the layer formed when the substrates were immerse in simulated body fluid $(\mathrm{SBF})$. The in vitro tests were carried out by soaking the composites bioactive glass/polyhydroxybutyrate 30/70 and 40/60 in SBF. The surface of the composites was analyzed by Scanning Electron Microscopy (SEM) with Energy Dispersive Spectroscopy (EDS) and also via $x$ ray Diffraction (XRD). The solutions were analyzed by Inductively Couple Plasma (ICP). SEM images show a formation of a Ca-P rich layer on surface of composites. XRD results characterized the layer as calcium hydrogen phosphate. $\mathrm{Ca} / \mathrm{P}$ ratios found via EDS results show a value close to 1.67. According to ICP results, the Ca e P ions are from SBF.
\end{abstract}

Keywords: bioactive glasses, polyhydroxybutyrate, composites and bioactivity

\section{Introduction}

The beginning of the 1980's hydroxyapatite/polyethylene composite was the first bioactive composite to be investigated ${ }^{1}$. These biomaterials have as the main aim to help the bone reparation. They can act as a viable alternative to autogenous grafts, because they can eliminate the donor surgical sites by decreasing the post-surgical discomfort of patients. Nearly all polymeric matrix developed as biomaterial is non-biodegradable; nevertheless biodegradable polymeric matrix has its importance such as ${ }^{2,3}$. The biodegradable composites have the advantage of allowing the natural growth of new tissue in order to maintain the load-bearing and function ${ }^{2}$.

According to Wang ${ }^{4}$ the quality of biomedical composites, e.g. mechanical properties, bioactivity, etc, are influenced by many factors, such as: size, shape and distribution of the reinforcement particles. The particle size will influence the reinforcement area. The particle shape can be spherical, irregular I, irregular II, acicular or parallel plates. The irregular I presents circular corners and the irregular II has shaped corners. Irregulars I and II have a lager surface area than the other shapes; lager it is, better the bioactivity will be. Glasses are produced having the irregular shape II, and therefore the glasses need to be milled to remove the shaped corners from the particles. The distribution factor of the reinforcement can be condensed - particles are hold together, dispersed - particles are spread out and intermediate. The dispersed distribution avoids crack initiation sites ${ }^{4,5}$. The reinforcement size can be uniform (mono-modal) or with different size (multi-modal, also called hybrid). The multimodal distribution, also avoids starting point of fracture ${ }^{6}$.

Polyhydroxybutyrate (PHB) belongs to the group of polyhydroxyalkanoates (PHA). This polymer is thermoplastic polyester that occurs naturally and is synthesized by many species of bacteria under nutrient deficiency ${ }^{7}$. It uses a renewable feedstock such as glucose $^{8}$. They need to respect some requirements to be used as biodegradable polymers, e.g. grafts. Among these requirements, the biocompatibility, the easy control of degradation, the non-toxicity of products from the degradation and easy excretion of these products stand out ${ }^{9}$. PHB has excellent properties of biocompatibility so much in tissue as in blood. The properties of biodegradability of PHB can be controlled and its degradation product (hydroxybutyric acid) is a common metabolite in human body ${ }^{10}$. Then, PHB attends to the requirements to be used as biomaterial.

The degradation of PHB and its copolymer hydroxyvalerate (HV) happen by hydrolysis in environments where extracellular enzymes from microorganisms are present; transforming the polymer in oligomers. These are finally transformed in carbon dioxide and water by intracellular enzymes ${ }^{11}$.

PHB was also used as reinforcement of hydroxyapatite ${ }^{2,7}$ and of tricalcium phosphate ${ }^{7}$. By reinforcing the PHB an increase of Young Modulus and micro-hardness were obtained. An increase of bioactivity was also observed in these composites. It might have induced a formation of linking hydroxyapatite.

Bioactive glasses are the first material that exhibits bioactive behavior ${ }^{12}$. The results for the tests carried out with bioactive glasses suggest that the precipitation of a Ca-P layer depends on the presence of $\mathrm{SiO}_{2}$. The silicate ions provide favorable sites for nucleation of apatite ${ }^{12,13}$. The formation of a layer rich in $\mathrm{Ca}$ and $\mathrm{P}$ follows a sequence of chemical reactions that ends with the formation of hydroxycarbonate apatite (HCA). Summarizing, the processes involved 
start with an exchange of ions from glass and from the solution and the formation of silanols $(\mathrm{SiOH})$ on surface of glass; later there is a loss of soluble silica and more formation of silanols. They condense and form a $\mathrm{SiO}_{2}$-rich layer, where a calcium phosphate coating is deposited. Finally, the Ca-P layer crystallizes and forms the HCA. This HCA layer needs to be well adhered to the implant and later it will adhere to bone assuring the osteointegration ${ }^{14}$. The presence of some components, such as $\mathrm{B}_{2} \mathrm{O}_{3}, \mathrm{CaF}_{2}, \mathrm{Fe}_{2} \mathrm{O}_{3}$, in bioactive glass can inhibit the formation of HCA surface layer or yet the addition of $\mathrm{Na}_{2} \mathrm{O}, \mathrm{P}_{2} \mathrm{O}_{5}$ can increase the formation of HCA layer ${ }^{12}$.

Hench et al. ${ }^{15}$ carried out in vitro studies using a tris-buffered solution to identify the sequence of reactions, which the HCA layer forms on bioactive glasses. In 1990, Kokubo et al. ${ }^{16}$ proposed a trisbuffered solution that simulates the body fluid, called as SBF-K9. It has similar ionic concentration found in human blood plasma. Since then, the SBF have been used as preliminary in vitro tests to be undertaken in new biomaterials.

Generally, glasses present disadvantages in the mechanical fields, because they have low mechanical properties. Glasses are brittle and they have low shear strength and short critical crack propagation length. The limited amount of network crystalline structure formed in glasses provides these pour properties, however it provides a good compressive strength ${ }^{17}$.

In the present work a composite, bioactive glass/PHB, was produced in order to have the bioactivity of the glass and structure of PHB. This novel composite will exhibit the capacity to form a Ca-P rich layer and to bond to the bone by the successive biodegradability of the bioactive glass and of the polymeric matrix. This composite will maintain the function of the bone while help the formation of a new tissue.

The main aim of this work was to evaluate the in vitro bioactivity of composite bioactive glass/PHB. After the composite was immersed in SBF x ray Diffraction (XRD), Scanning Electron Microscopy (SEM), Energy Dispersive Spectroscopy (EDS) were used to characterize the Ca-P layer formed on composites and the solutions were analyzed by Inductively Couple Plasma (ICP).

\section{Materials and Methods}

A bioactive glass named $\mathrm{VH} 30$ was produced from the composition $32.76 \mathrm{SiO}_{2}-40.443 \mathrm{CaO} . \mathrm{P}_{2} \mathrm{O}_{5}-26.8 \mathrm{MgO}$. The reagents $\mathrm{SiO}_{2}$, $\mathrm{MgO}, \mathrm{CaCO}_{3}$ and $\mathrm{Ca}\left(\mathrm{H}_{2} \mathrm{PO}_{4}\right)_{2}$ were mixed manually with $96 \%$ ethylic alcohol and put into the planetary mill (Fritsh Pulveresette) using an agate lined jar and agate balls for 45 minutes to make a homogeneous mixture. The mixture was put in the stove (Memmert) at $60{ }^{\circ} \mathrm{C}$ for 24 hours to be dried. Mixture batches were smashed to transform them into powder again. Batches with $80 \mathrm{~g}$ were melted in platinum crucible at a temperature of $1500{ }^{\circ} \mathrm{C}$ in a cylindrical oven (Termolab) for one hour. The melts were poured quickly to a bucket with water to have a fast cooling. The glass samples were dried in a stove (Memmert) for 24 hours. The samples were grinded in an agate mill (Retsh MR 100) for one hour and sieved manually in a $30 \mu \mathrm{m}$ mesh. Particles retained on the sieve were separated. The final material obtained was a $\mathrm{SiO}_{2}-\mathrm{CaO}-\mathrm{MgO}-\mathrm{P}_{2} \mathrm{O}_{5}$ glass powder.

Coulter (LS Particle Size Analyzer) test was used to analyze the glass particles size using a Fraunhofer optical model in water as fluid to obtain medium size of the glass particles. BET (Gemini 2370 V5.00) test was used in a sample of $0.7275 \mathrm{~g}$ of glass at a $300 \mathrm{mmHg}$ / min evacuation rate and under saturation pressure of $786 \mathrm{~mm} \mathrm{Hg}$ to obtain the surface area of the powder. The glass was also characterized by $\mathrm{x}$ ray Diffraction to confirm its amorphous nature using $\mathrm{CuK} \alpha$ radiation $(40 \mathrm{kV}$ and $30 \mathrm{~mA})$.

The poly(3-hydroxyburyrate) used was synthesized by Burkholderia sacchari under nitrogen deficiency and present less than $3 \%$ of copolymer hydroxyvalerate (HV). The molar mass is about $250.000 \mathrm{~g} / \mathrm{mol}$ and the melting point is $162{ }^{\circ} \mathrm{C}$. The polymer was donated by Department of Chemical Engineering of University of Coimbra.

Composites bioactive glass/PHB in relations 30/70 and 40/60 wt. (\%) was prepared following these steps: 300 or $400 \mathrm{mg}$ of bioactive glass were mixture with acetone and 700 or $600 \mathrm{mg}$ of PHB was added to the mixture, respectively, to perform $1 \mathrm{~g}$ of composite; after manual homogenization the samples were dried under $60^{\circ} \mathrm{C}$ for 24 hours in a stove (Memmert); the samples were put in a cylindrical mold of $1 \mathrm{~cm}$ of diameter and taken to a hot press (Carvers Laboratory Press $\mathrm{C}$ ). The molding was undertaken under $150{ }^{\circ} \mathrm{C}$ and under a load of 3 ton for $30 \mathrm{~min}$. After cooling the 30 samples of composite bioactive glass 30/70 and 40/60 were took in 2 different flasks.

Microhardness Vickers assay was carried out in 2 samples of each composite 30/70 and 40/60. They were polished with sandpapers in the sequence: 120, 500, 800 and 1200. The samples were cleaned by immersing them in distillated water and put them in ultrasonic bath for 20 minutes. The samples were dryed in a room temperature. Microhardness Vickers measurements were undertaken via microdurometer Shimadzu Type M using a $300 \mathrm{~g}$ of load for 15 seconds. Twenty measurements were done for each composite.

$\mathrm{SBF}$ was prepared by mixing the reagents $\mathrm{NaCl}, \mathrm{NaHCO}_{3}$, $\mathrm{KCl}, \mathrm{K}_{2} \mathrm{HPO}_{4} .3 \mathrm{H}_{2} \mathrm{O}, \mathrm{MgCl}_{2} \cdot 6 \mathrm{H}_{2} \mathrm{O}, \mathrm{HCl}, \mathrm{CaCl}_{2} \cdot 6 \mathrm{H}_{2} \mathrm{O}, \mathrm{Na}_{2} \mathrm{SO}_{4}$, $\mathrm{NH}_{2} \mathrm{C}\left(\mathrm{CH}_{2} \mathrm{OH}\right)_{3}=\mathrm{C}_{4} \mathrm{H}_{11} \mathrm{NO}_{3}$ in $500 \mathrm{~mL}$ of ultra pure water in a beaker according to the method proposed by Kokubo et al. ${ }^{16}$. The solution had a $\mathrm{pH}=7.25$ corrected by $\mathrm{HCl} 1 \mathrm{~N}$. The solution was transferred to a chemical flask and it was added ultra pure water to complete $1 \mathrm{~L}$. The SBF ionic concentration simulates the human plasma, and has the chemical composition presented in Table 1.

The in vitro tests were undertaken immersing the circular tablets $(5 \times 10 \mathrm{~mm})$ of composites bioactive glass/PHB 30/70 and 40/60 in 12 different flasks containing SBF. The samples were sterilized by $\mathrm{UV}$ radiation for 20 minutes for each side of the tablets. The samples were put in a stove under $37{ }^{\circ} \mathrm{C}$ for 2 and 7 hours and 1, 3, 7 and 14 days. After these periods the samples were withdrawn from the solution and dried in room temperature; the solution was kept in a refrigerator under $5^{\circ} \mathrm{C}$. The formation of a Ca-P rich layer in surface of both composites was observed via Scanning Electron Microscopy (SEM) (Hitachi S4100) and the characterization of composition of the layer was undertaken by Energy Dispersive Spectroscopy (EDS) (Rontec). The identification of the phase present in the Ca-P layer was carried out by x ray Diffraction (XRD) (Rigaku PMG-VH), at $\mathrm{Cu} \mathrm{K} \alpha$ radiation $(40 \mathrm{kV}$ and $30 \mathrm{~mA}$ ).

The chemical compositions of the solutions, that soaked the samples of composites, were analyzed by Inductively Couple Plasma (ICP) (Jobin-Yvon JY70 Plus Spectrometer), to evaluate the exchange of ions from the samples and the solutions.

Table 1. Ions concentration $(\mathrm{mM})$ in plasma and in $\mathrm{SBF}^{16}$.

\begin{tabular}{lccccccccc}
\hline & $\mathrm{Na}^{+}$ & $\mathrm{K}^{+}$ & $\mathrm{Ca}^{2+}$ & $\mathrm{Mg}^{2+}$ & $\mathrm{Cl}^{-}$ & $\mathrm{HCO}_{3}^{-}$ & $\mathrm{HPO}_{4}^{-}$ & $\mathrm{SO}_{4}^{2-}$ \\
\hline Plasma & 142.0 & 5.0 & 2.5 & 1.5 & 103.0 & 27.0 & 1.0 & 0.5 \\
SBF & 142.0 & 5.0 & 2.5 & 1.5 & 148.8 & 4.2 & 1.0 & 0.5 \\
\hline
\end{tabular}




\section{Results and Discussion}

The average size of particles of bioactive glass was about $10.50 \pm 9.4 \mu \mathrm{m}$. The particle size presents a high standard deviation value. It can provide an ideal distribution - hybrid distribution - of the reinforcement particles in the composites, considering that the reinforcements present a great homogenization ${ }^{6}$. Figures 1-2 are SEM images of the composite bioactive glass/PHB, 30/70 and 40/60, respectively. As it can be observed the reinforcements are distributed randomly. Both samples present a hybrid distribution, however the sample bioactive glass/PHB 40/60 is the one that the particles present more size variation. The hybrid distribution increases the probability of the presence of the bioactive glass (reinforcement) in any part of the composite, decreasing the chance to crack propagation ${ }^{19}$. Its mechanical properties tend to be better than the bioactive glass/PHB 30/70. The average particle size results of this work are in agreement with the results found by others. The value $10.50 \pm 9.4 \mu \mathrm{m}$ is close to the average size of composites tricalcium phosphate/PHB $(4.4 \mu \mathrm{m})$ used by Wang et al. ${ }^{2}$ and close to composites hydroxyapatite/PHB $(24.5 \mu \mathrm{m})$ used by Ni and Wang ${ }^{20}$. They show bioactivity when immersed in SBF.

Jaakkola et al. ${ }^{21}$ concluded that the quantity of bioactive glass and the size of particles influence the bioactivity of composite. Larger particles and high quantity of particles presented less bioactivity than

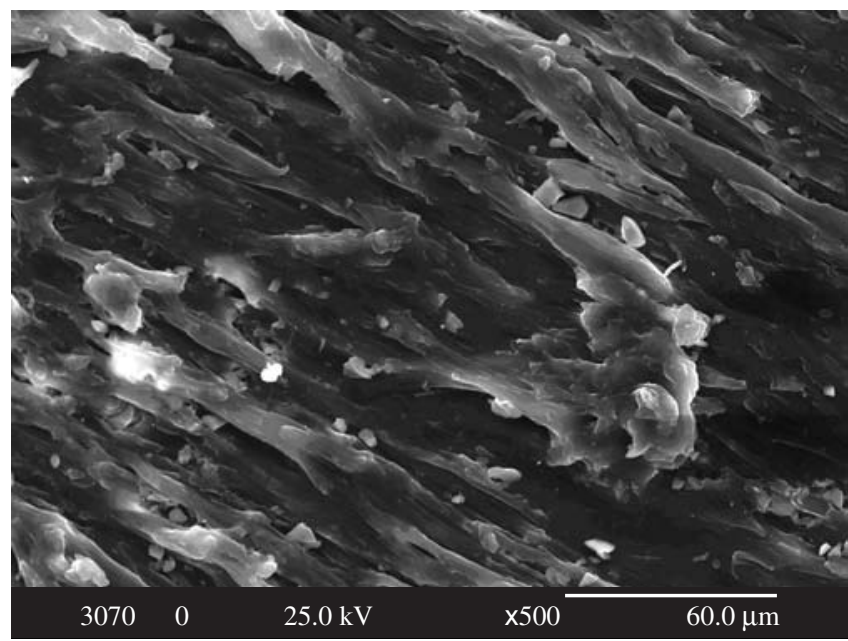

Figure 1. SEM image of composite bioactive glass/PHB 30/70 as prepared

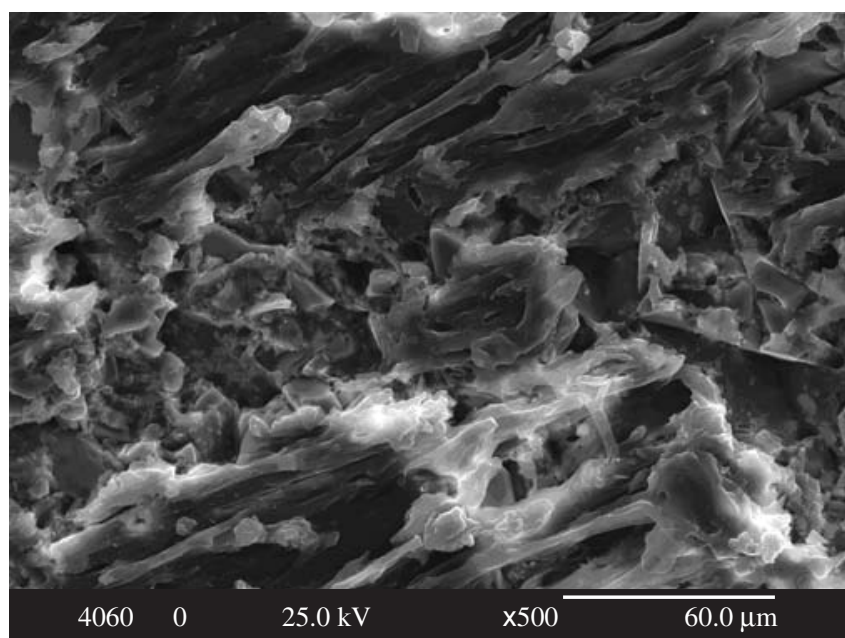

Figure 2. SEM image of composite bioactive glass/PHB 40/60 as prepared composite with smaller particles and intermediate size particles. The authors used 40, 60 and 70 percent of bioactive glass with size particle of $>45 \mu \mathrm{m}$ and 90-135 $\mu \mathrm{m}$ in composites $\varepsilon$-caprolactone-co-DL-lactate/bioactive glass. However, $\mathrm{Ni}$ and $\mathrm{Wang}^{20}$, produced composites HA/PHB with less percentage of HA (10, 20 and 30\%) and obtained a great formation of apatite layer, which indicates a higher bioactive with less quantity of hydroxyapatite.

The values of surface areas, BET results, for the bioactive glass were $0.7583 \mathrm{~m}^{2} . \mathrm{g}^{-1}$ and $0.6685 \mathrm{~m}^{2} . \mathrm{g}^{-1}$ in the multipoint mode and in the single point method, respectively. Zhong et al. ${ }^{22}$, affirm that only bioactive glasses with surface area larger than $40-80 \mathrm{~m}^{2} . \mathrm{g}^{-1} \mathrm{can}$ induce HCA formation. However, Krajewski et al. ${ }^{23}$ produced bioactive glass and common glasses with surface area between 0.083 and $0.255 \mathrm{~m}^{2} \cdot \mathrm{g}^{-1}$ and concluded that the bioactive glass with smaller surface areas also show some bioactivity. The surface area values of the bioactive glass, produced in the present work, are among the values obtained by Krajewski and Zhon and collaborators ${ }^{22,23}$. Regarding to the bioactivity, the surface area values of the samples produced in this work also exhibit bioactivity.

The microhardness Vickers results are presented in the Table 2. The results obtained for the bioactive glass/PHB 30/70 and 40/60 composites were superior to the results found by Chen and Wang ${ }^{7}$, when TCP/PHB and HA/PHB composites (30\% of reinforcement) were studied, $10.18 \pm$ 0.16 and $15.73 \pm 0.44(\mathrm{VHN})$ respectively. However, they were similar to the results obtained by Wang et al. ${ }^{3}$ in composite $30 \mathrm{TCP} / 70 \mathrm{PHB}$ $(24.66 \pm 1.05 \mathrm{VHN})$. According to $\mathrm{Wang}^{4}$ and Doyler et al. ${ }^{9}$ higher is the quantity of ceramics higher will be the stiffness and there is a straight relationship between microhardness Vickers and Young Modulus. Therefore, the quantities of HA can also affect the bioactivity of material. The authors mentioned that the bioactivity is improved when the percentage of ceramic is between 20 and $40 \%$. This amount of ceramic might not give the necessary mechanical properties to the composite; there is a need of increasing the amount of reinforcement. A balance between mechanical property and bioactivity needs to be found.

SEM results are presented in Figures 1-6. Composite bioactive glass/PHB 30/70 and 40/60, as prepared, are shown in Figures 1

Table 2. Microhardness Vickers.

\begin{tabular}{cc}
\hline Composite & Microhardness (VHN) \\
\hline $40 / 60$ & $24.6 \pm 3.0$ \\
$30 / 70$ & $23.6 \pm 2.5$ \\
\hline
\end{tabular}

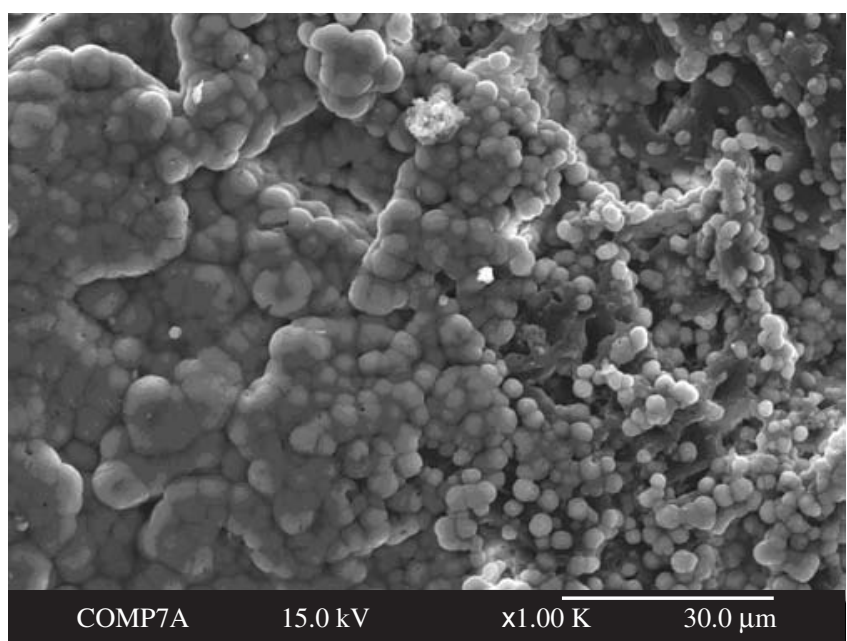

Figure 3. SEM image of composite bioactive glass/PHB 30/70 after 7 days of immersion in SBF. 


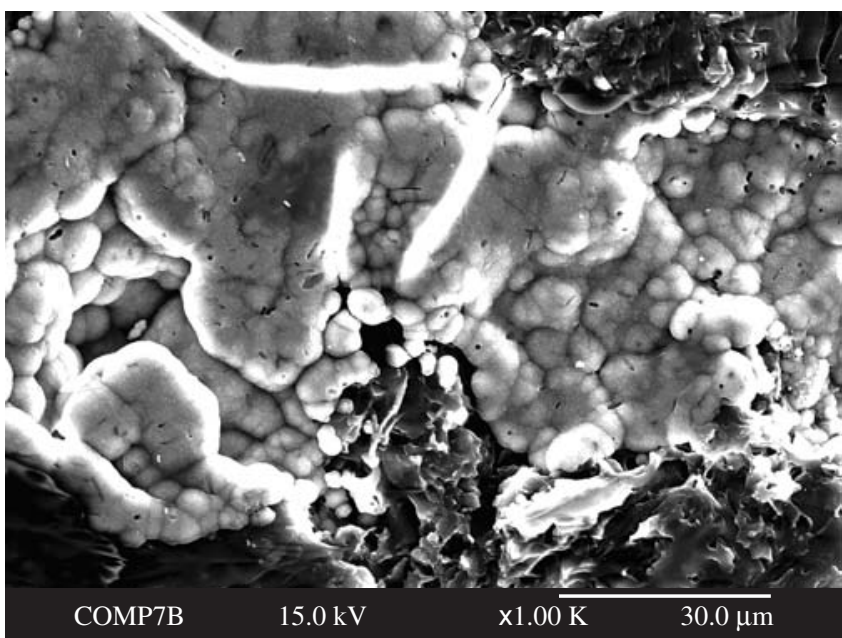

Figure 4. SEM image of composite bioactive glass/PHB 40/60 after 7 days of immersion in SBF

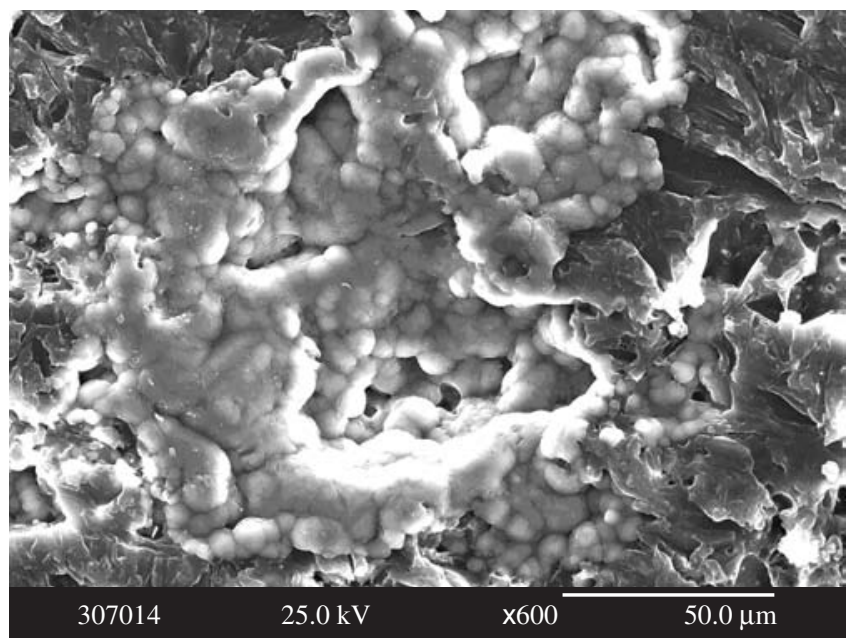

Figure 5. SEM image of composite bioactive glass/PHB 30/70 after 14 days of immersion in SBF

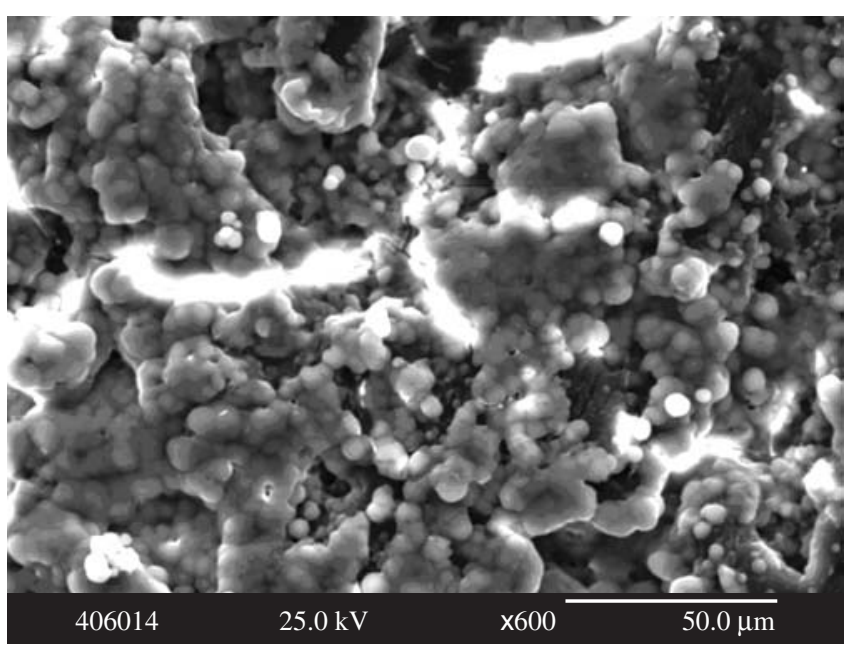

Figure 6. SEM image of composite bioactive glass/PHB 40/60 after 14 days of immersion in SBF.

and 2, respectively. The morphology of layer formed on the composite bioactive glass/PHB 30/70 after 7 days immersed in SBF is presented in Figure 3. It can be observed that this layer presented globular morphology. The globular morphology found by Jaakkola ${ }^{21}$ on the composite $\varepsilon$-caprolactone-co-DL-lactate/bioactive glass after 7 days of soaking in SBF is similar to the morphology found in this work. Chen and Wang ${ }^{7}$ also observed similar morphology formed on composites HA/PHB after 28 days immersed in SBF. Figure 4 show a layer formation on the composite bioactive glass/PHB 40/60 after 7 days of immersion in SBF and its morphology resembles the one found by $\mathrm{Ni}$ and Wang ${ }^{20}$ when composites HA/PHB were immersed in SBF during 7 days. Comparing the morphology of the layer formed on the composites used in this work, the layer formed on the bioactive glass/PHB 30/70 is more uniform and continuous than the layer formed on composite bioactive glass/PHB 40/60, Figures 3 and 4. It was observed a continuous formation of globular layers, however even more cohesive and uniform, when the in vitro studies were prolonged to 14 days on both composites, Figures 5 and 6 . Roether et al. ${ }^{24}$ using porous composite poly(DL-lactide)/Bioglass ${ }^{\circledR}$ found similar morphology in layers formed in samples immersed in SBF. The authors observed the growth of HA on composite surface after 7 days of soaking in SBF, however the similar morphology was only observed after 28 days of immersion in SBF. It indicates a better bioactivity of the composites produced in this work than the one produced by Roether et al. ${ }^{24}$.

HA morphology can vary from acicular to equi-axed crystals and it depends on the concentration of ion carbonate $\left(\mathrm{CO}_{3}^{-}\right)^{25}$. All biologic apatites show a percentage of carbonate, $\mathrm{CO}_{3}{ }^{-}$and the globular morphology has about $12.5 \%$ of $\mathrm{CO}_{3}{ }^{-}$. The morphology observed via SEM is in agreement with the spherical format of HCA. The adherence of HCA layer on the composite will depend of the chemical interactions and thickness and it will influence the adhesion of the cells, orienting, for example, the formation of the conjunctive tissue ${ }^{26}$.

EDS results are presented in Figures 7-9. As it can be observed there is an intense formation of Ca-P rich layer. EDS spectrograms show clearly difference between intensity of $\mathrm{Ca}$ and $\mathrm{P}$ in the composites as prepared (Figure 8 ) and in the composites bioactive glass/PHB $30 / 70$ and 40/60, after immersion in SBF during 14 days, Figures 8 and 9, respectively. The $\mathrm{Ca} / \mathrm{P}$ ratio of the layer formed on bioactive glass/PHB 30/70 is near to the 1.67 , which is the $\mathrm{Ca} / \mathrm{P}$ ratio of $\mathrm{HA}$ of the human body ${ }^{25}$. The $\mathrm{Ca} / \mathrm{P}$ ratio $\approx 1.67$ of $\mathrm{Ca}-\mathrm{P}$ layer deposited on the bioactive glass/PHB 30/70 was maintained constant for different time of immersion in SBF. Composite bioactive glass/PHB 40/60 did not show a constant $\mathrm{Ca} / \mathrm{P}$ ratio for different time of immersion in SBF; however these values were between 1.0 to 2.0 that are typical of other phases present in human body.

In vitro studies of composite bioactive glass/PHB, carried out in the present work, showed that the composite with $30 \%$ of bioactive glass forms a Ca-P rich layer faster and more uniform than the composite with $40 \%$ of bioactive glass, Figures 3-4, respectively. There is a tendency in other works to use composites ceramics/polymers between 20 to $40 \%$ of ceramics reinforcements, because these percentages have shown a better bioactive behaviour ${ }^{5,7,9,20}$. It suggests that composite $30 / 70$ is more bioactivity than composite $40 / 60$.

XRD spectra of bioactive glass/PHB 30/70 and 40/60 after 3 days of immersion in SBF are presented in the Figures 10 and 11, respectively. Calcium hydrogen phosphate peaks are present in both samples; however they show up with low intensity due to the few days of immersion. As describe by Peitl ${ }^{14}$, initially an amorphous layer of calcium phosphate forms and after the incorporation of ions $\mathrm{OH}^{-}$and $\mathrm{CO}_{3}{ }^{-}$the crystallization of $\mathrm{HCA}$ starts. These results suggest that 3 days of immersion in SBF is not enough to have the complete crystallization.

The change in the concentration of ions in SBF used in the in vitro studies of the samples of bioactive glass/PHB 30/70 and 40/60 


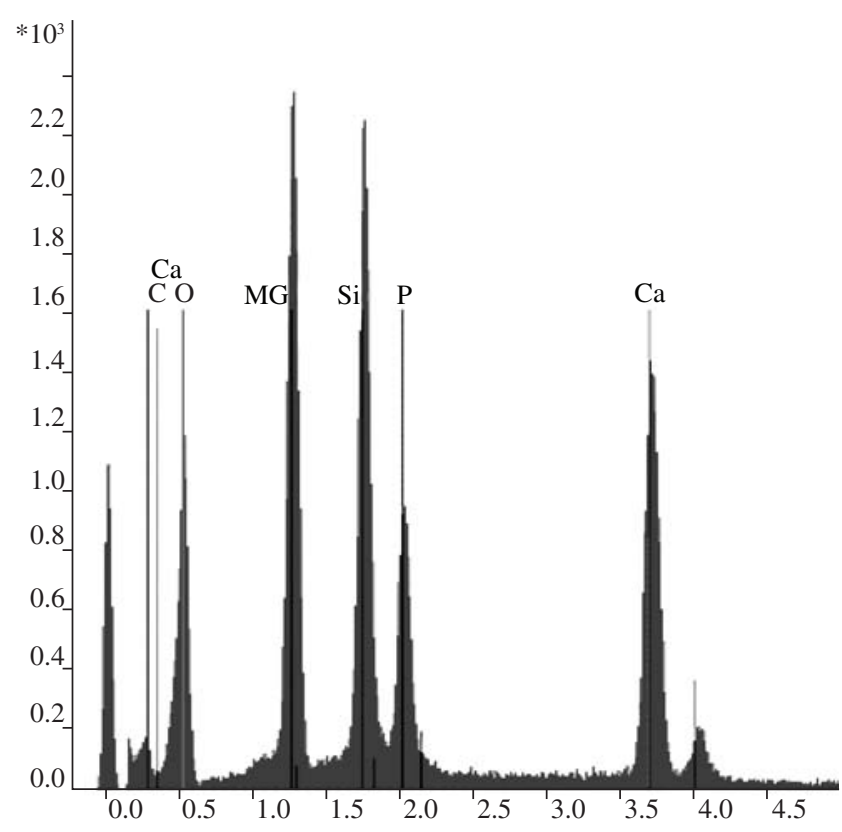

(a)

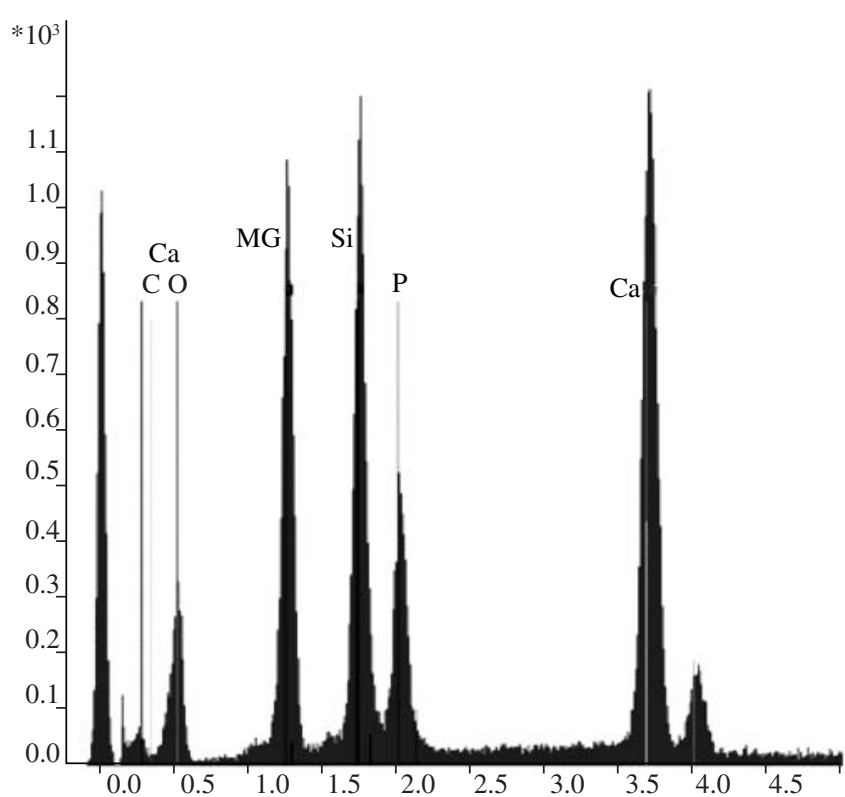

(b)

Figure 7. EDS spectrogram of composites bioactive glass/PHB 30/70 (a) and 40/60 (b) as prepared.

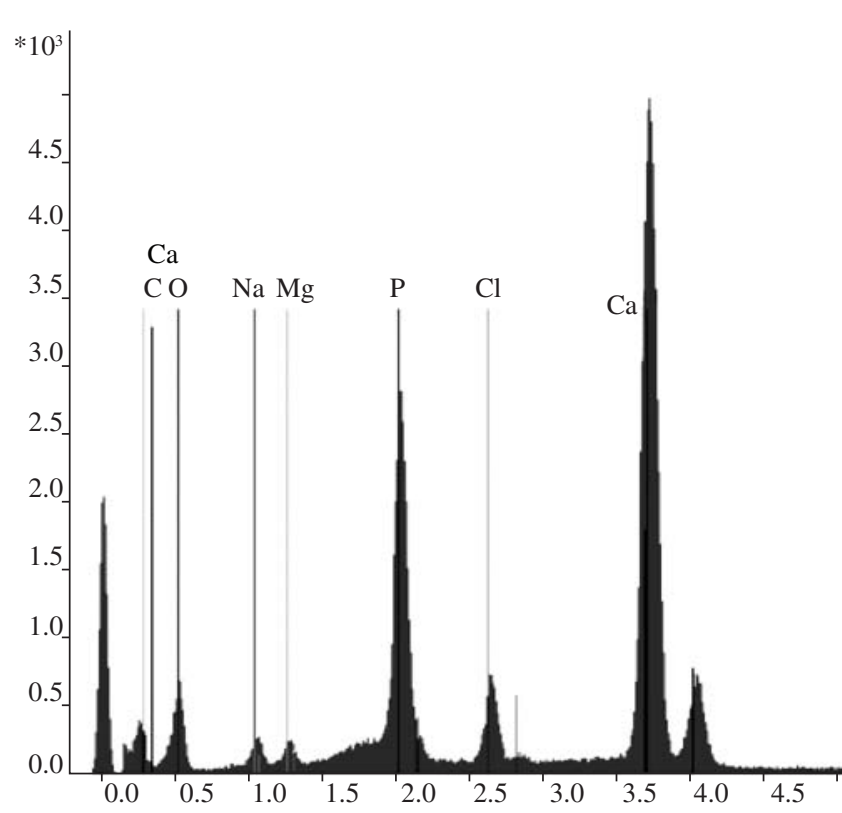

Figure 8. EDS spectrogram of bioactive glass/PHB 30/70 after 7 days.

can be seen in the Figures 12 and 13, respectively. In the first stage, there is dissolution of all ions present in the glass structure. Therefore, after 1day, the concentration of ions $\mathrm{Ca}$ and $\mathrm{P}$ start to decrease. Concomitantly, $\mathrm{Ca}$ and $\mathrm{P}$ ions are being deposited on the composite as presented in the Figure 3-6. The concentration of $\mathrm{Si}$ and $\mathrm{Mg}$ ions in the SBF increasing continually; indicating the degradation of bioactive glass. The ICP results are similar to other works ${ }^{14,27,28}$. Jaakkola et al. ${ }^{21}$ state that the dissolution of Si from the bioactive glass is one the indicator of bioactivity and it is higher for composites that have smaller particles size of bioactive glass.

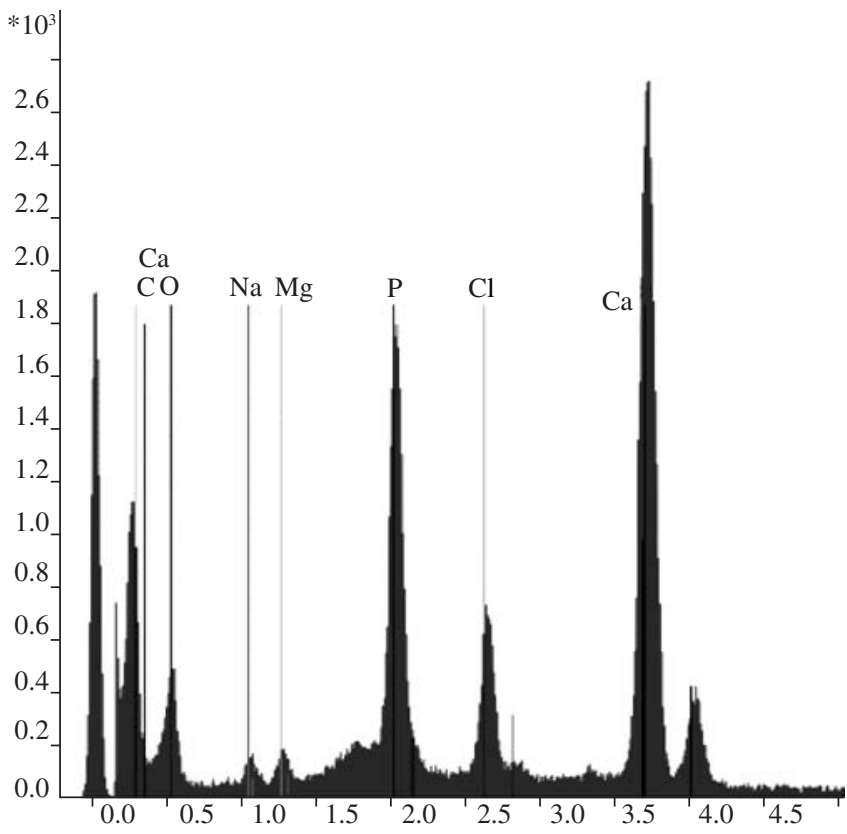

Figure 9. EDS spectrogram of bioactive glass/PHB 30/70 after 7 days.

\section{Conclusions}

The microhardness of bioactive glass/PHB 40/60 and 30/70 composites are $24.291 \pm 8.76 \mathrm{HV}$ and $25.273 \pm 10.82 \mathrm{HV}$, respectively. In vitro studies show that Bioglass/PHB composites (30/70 and 40/60) have formed a layer of $\mathrm{Ca}$-P. It can be suggest that these composites have enough bioactivity to be used as biomaterial. The composites bioglass/PHB 30/70 form a Ca-P rich layer faster than bioglass/PHB 40/60. The Ca-P layer formed on bioglass/PHB 30/70 has a $\mathrm{Ca} / \mathrm{P}$ ratio of approximately 1.67 , which is the $\mathrm{Ca} / \mathrm{P}$ of $\mathrm{HA}$ found in human body. 


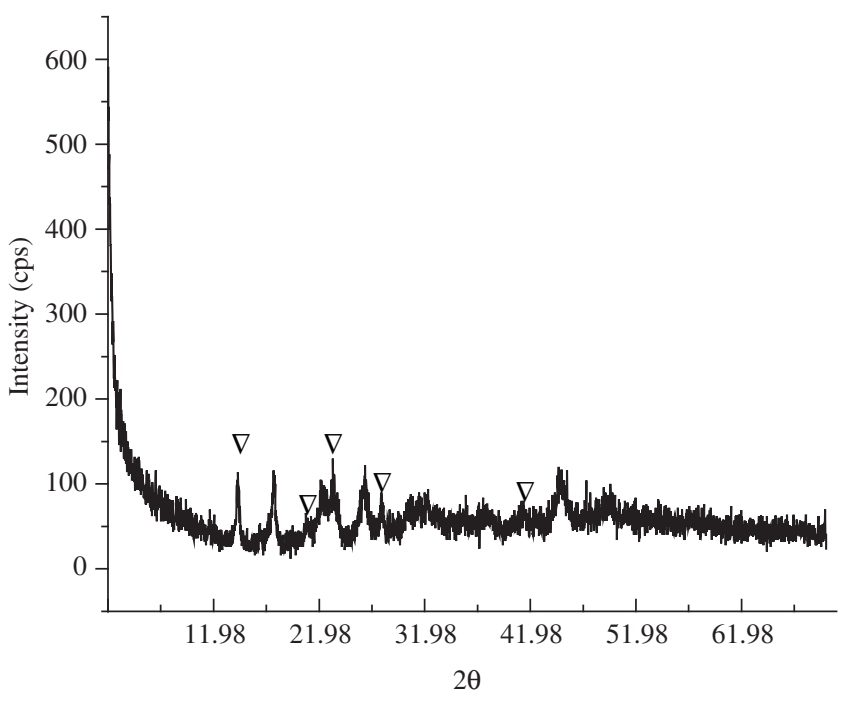

Figure 10. XRD spectrum of bioactive glass/PHB 30/70 after 7 days of immersion in SBF ( $\nabla$ Calcium Hydrogen Phosphate).

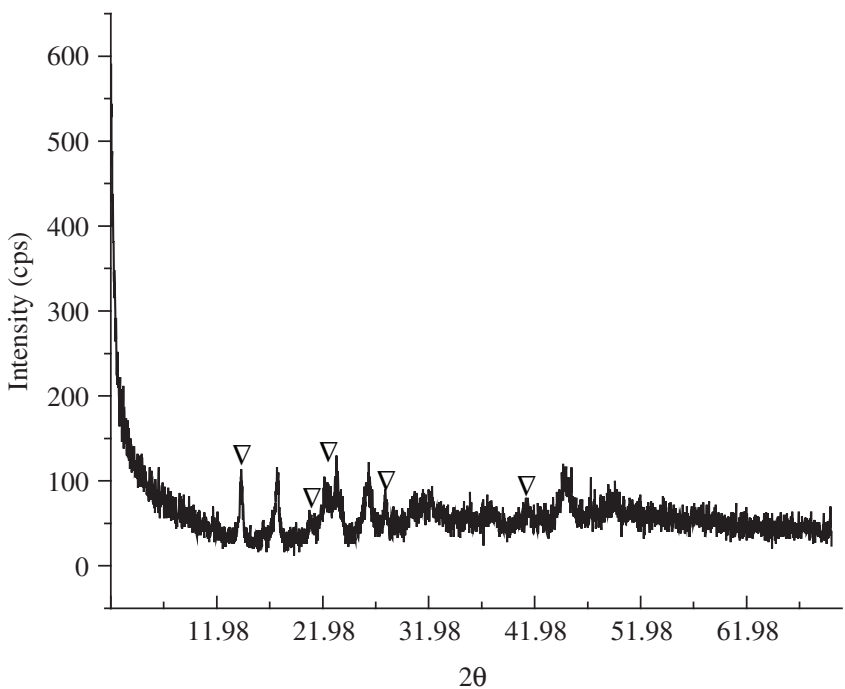

Figure 11. XRD spectrum of bioactive glass/PHB 40/60 after 7 days of immersion in SBF ( $\nabla$ Calcium Hydrogen Phosphate).

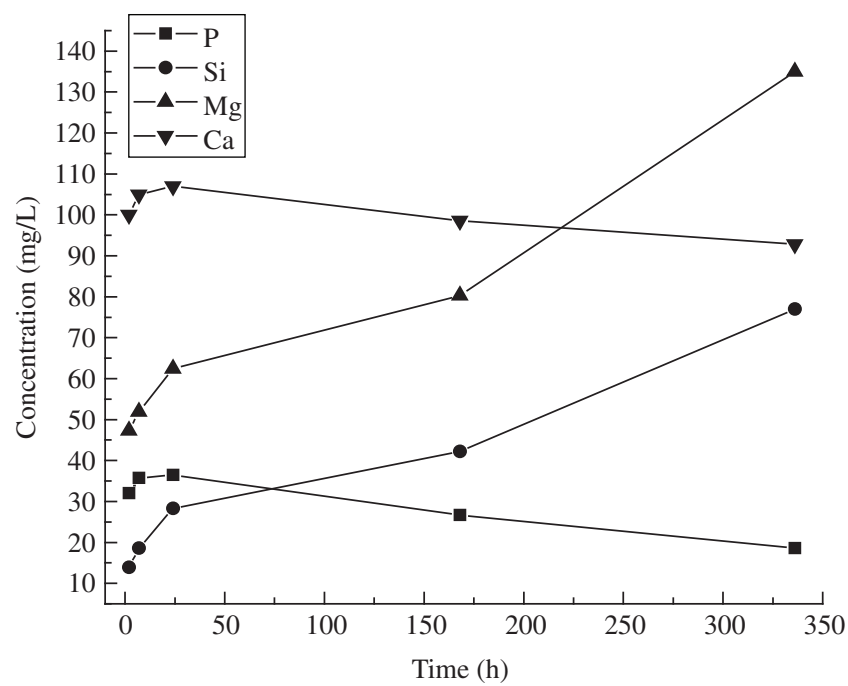

Figure 12. ICP results of solution that soaks bioactive glass/PHB 30/70.

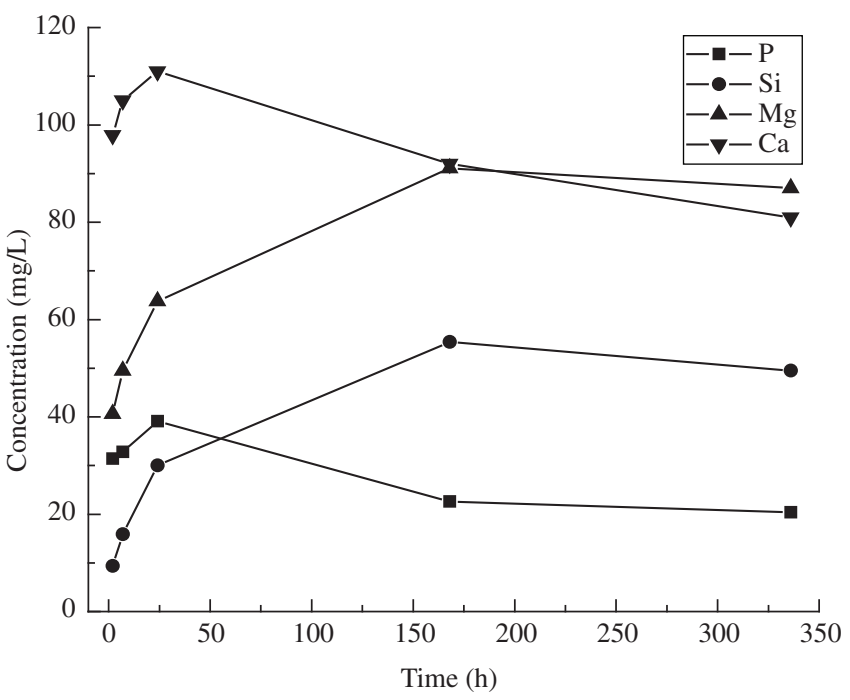

Figure 13. ICP results of solution that soaks bioactive glass/PHB 40/60.

The $\mathrm{Ca} / \mathrm{P}$ ratio found in the bioglass/PHB 40/60 did not present constant values; on the other hand they were between 1.1 and 1.9 that correspond to other phases of calcium phosphate. The HA layer formed on the bioglass/PHB 40/60 and bioglass/PHB 30/70 after being immersed in SBF during 3 days are not uniform. It presents some areas of cristalinity and others amorphous. The depletion of $\mathrm{Ca}$ and $\mathrm{P}$ in the $\mathrm{SBF}$ of ions $\mathrm{Ca}$ and $\mathrm{P}$ present in the calcium phosphate layer are from the SBF.

\section{Acknowledgment}

We are grateful to CAPES for the financial support and to Sandra Cachinho for the precious help.

\section{References}

1. Bonfield W, Grynpas MD, Tully AE, Bowman J, Abram J. Hydroxyapatite reinforced polyethylene - a mechanically compatible implant material for bone replacement. Biomaterials. 1981; 2(3):185-186.

2. Wang M. et al. Developing Tricalcium Phosphate/ Polyhydroxybutyrate composite as a new biodegradable material for clinical applications. Bioceramics. 2001; 1(3):193-195.

3. Ramakrishna S, Mayer J, Wintermantel E, Leong KW. Biomedical application of polymer composite material: a review. Composites Science and Technology. 2001; 61(3-4):1189-1224.

4. Wang M. Developing bioactive composite materials for tissue replacement. Biomaterials. 2003; 24(13):2133-2151.

5. Wang M, Bonfield W. Processing, characterization, and evaluation of hydroxyapatite reinforced polyethylene composites. Br. Ceram Trans. 1994; 93(3):91-95.

6. Anusavice KJ. Philips: Materiais Dentários. 10a ed. Rio de Janeiro: Guanabara Koogan; 1998.

7. Chen L, Wang M. Production and evaluation of biodegradable composites based on PHB-PHV copolymer. Biomaterials. 2002; 23(13):2631-2639.

8. Owen AJ, Henzel J, Škrbić Ž, Divjaković. Crystallization and melting behaviour of PHB and PHB/HV copolymer. Polymer. 1992; 33(7):1563-1567.

9. Doyle C, Tanner ET. Bonfiel W. In vitro and in vivo evaluation of polyhydroxybutyrate and of polyhydroxybutyrate reinforced with hydroxyapatite. Biomaterials. 1991; 12(9):841-847.

10. Freier T, Kunze C, Nischan C, Kramer S, Sternberg K, Saß M. Hopt UT, Schmitz KP. In vitro and in vivo degradation studies for development of a biodegradable patch base on poly(3-hydroxybutyrate). Biomaterials. 2002; 23(13):2649-2657. 
11. Nurbas NM, Kutsal T. Production of Polyhydroxyalkanoate (PHA) by Alcaligenes eutrophus. National Chemical Engineering Congress; Middle East Technical University, Ankara; 1994.

12. Oliveira JM, Correia RN, Fernades MH. Surface modifications of a glass and a glass-ceramic of the $\mathrm{MgO}-3 \mathrm{CaO} . \mathrm{P}_{2} \mathrm{O}_{5}-\mathrm{SiO}_{2}$ system in a simulated body fluid. Biomaterials. 1995; 16(11):849-854.

13. Hench LL, Wilson J. An introduction to bioceramics. $1^{\text {st }}$ ed. World Scientific: Singapore; 1993.

14. Peitl O, Zanotto ED, Hench LL. Higly bioactive $\mathrm{P}_{2} \mathrm{O}_{5}-\mathrm{Na} 2 \mathrm{O}-\mathrm{CaO}$ $\mathrm{SiO}_{2}$ glass-ceramics. J. Non-Cryst Solids. 2001; 292(1-3):115-126.

15. Hench LL, Splinter RJ, Allen WC, Greenlee TK. Bonding mechanisms at the interface of ceramic prosthetic materials. J Biomed Mater Res Symp. 1971; (2):117-141.

16. Kokubo T, Kushitani H, Ohtsuki C, Yamamuro T. Chemical reaction of bioactive glass and galss-ceramic with a simulated body fluid. J. Mater Sci: Materials in Medicine. 1992; 3(2):79-83.

17. Heikkilä JT, Aho AJ, Kangasniemi I, Yli-Urpo A. Polymethylmethacrylate composites: disturbed bone formation ate the surface of bioactive glass and hydroxyapatite. Biomaterials. 1996; 17(18):1755-1760.

18. Yoshie N, Saito M, Inoue Y. Effect of chemical compositional distribution on solid-state structures and properties of poly(3-hydroxybytrurte-co-3hydroxyvalerate). Polymer. 2004; 45(6):1903-1911.

19. Schwartz MM, editor. Composite materials handbook. $2^{\text {nd }}$ ed. New York: McGraw-Hill; 1992
20. Ni J, Wang M. In vitro evaluation of hydroxybutyrate reinforced polyhydroxybutyrate composite. Mat. Sci and Eng. 2002; 20(1-2):101-109.

21. Jaakkola T, Rich J, Tirri T, Närhi T, Jokinen M, Seppälä J, Yli-Urpo A. In vitro Ca-P precipitation on biodegradable thermoplastic composite of poly(e-caprolactone-co-dl-lactide) and bioactive glass (S53P4). Biomaterials. 2004; 25(4):575-581.

22. Zhong JP, Greenspan DC, Feng JW. A microstructural examination of apatite induced by Bioglass ${ }^{\circledR}$ in vitro. J Mat Sci: Materials In Medicine. 2002; 13(3):321-326.

23. Krajewsk A, Malavolti R, Piancastelli A. Albumin adhesion on some biological and non-biological glasses and connection with their Z-potentials. Biomaterials. 1996; 17(1): 53-60.

24. Roether J. et al. Development and in vitro characterization of novel bioresorbable and bioactive composite materials based on polylactide foams and Bioglass ${ }^{\circledR}$ for tissue engineering applications. Biomaterials. 2002; 23(18):3871-3878

25. Le Geros RZ. Apatites in Biological Systems Prog. Crystal Growth Charact. 1981; 4(1-2):1-45.

26. Costa N, Maquis PM. Biomimetic processing of calcium phosphate coating. Medical Engineering \& Physics. 1998; 20(8):602-606.

27. Leonor I. et al. In situ study of partially crystallized Bioglass ${ }^{\circledR}$ and hydroxyapatite in vitro bioactivity using atomic force microscopy. J Biomed Mater Res. 2002; 62(1):82-88.

28. Oréfice RL, et al. In vitro bioactivity of polymer matrices reinforced with a bioactive glass phase. J Braz. Chem. Soc. 2000; 11(1):78-85. 
